\title{
TITLE:
}

\section{Catalytic dehydrative peptide synthesis with gem-diboronic acids}

$\operatorname{AUTHOR}(\mathrm{S})$ :

Michigami, Kenichi; Sakaguchi, Tatsuhiko;

Takemoto, Yoshiji

\section{CITATION:}

Michigami, Kenichi ... [et al]. Catalytic dehydrative peptide synthesis with gem-diboronic acids. ACS Catalysis 2020, 10(1): 683-688

\section{ISSUE DATE:}

2020-01-03

URL:

http://hdl.handle.net/2433/245796

\section{RIGHT:}

This document is the Accepted Manuscript version of a Published Work that appeared in final form in ACS Catalysis, copyright (C) American Chemical Society after peer review and technical editing by the publisher. To access the final edited and published work see https://doi.org/10.1021/acscatal.9b03894.; The full-text file will be made open to the public on 12 December 2020 in accordance with publisher's 'Terms and Conditions for Self-Archiving'.; This is not the published version. Please cite only the published version.; この論文は出版社版でありません。引用の際には出版社版 をご確認ご利用ください。 


\title{
Catalytic Dehydrative Peptide Synthesis with gem-Diboronic Acids
}

\author{
Kenichi Michigami, Tatsuhiko Sakaguchi, Yoshiji Takemoto* \\ Graduate School of Pharmaceutical Sciences, Kyoto University, Kyoto 606-8501, Japan
}

\author{
Supporting Information Placeholder
}

\begin{abstract}
Alkane-gem-diboronic acids have emerged as versatile organoboron catalysts for dehydrative amidation of $\alpha$-amino acids. A phenol-substituted multi-boron catalyst with a B-C-B structure outperformed simple arylboronic acids in the condensation of $\alpha$-amino acids with suppressed epimerization of electrophiles. gem-diboronic acid catalysis were compatible with various $O, N$, and $S$-functionalized $\alpha$-amino acids bearing $N$-protecting groups including common carbamates used in peptide synthesis (Boc, Cbz, Fmoc). $N$-trifluoroacetyl protection enabled an unprecedented catalytic dehydrative peptide synthesis at room temperature. Preliminary mechanistic studies revealed carboxylate-binding nature of gem-diboronic acids, orthogonal to the activation of carboxylic acids by arylboronic acids. The distinctive reactivity of the gem-diboronic acids would open prospects for mild catalytic peptide condensation.
\end{abstract}

keywords: organoboron catalyst, gem-diboronic acid, dehydrative amidation, peptide synthesis, oligopeptide, carboxylate activation

In the last half century, the practical synthesis using low-electrophilic carboxylic acids has been broadened by virtue of condensation reagents. ${ }^{1}$ In particular, reagent-driven dehydrative amidation has largely contributed to the mass production of amide-containing entities, including artificial pharmaceuticals, bioactive peptides, and functional polymers. ${ }^{2}$ Therefore, this highly reliable methodology is still in the forefront of organic synthesis, notwithstanding the stoichiometric generation of chemical wastes. In contrast, the recent high demand for environment-friendly alternatives has led to the exploitation of catalytic amide $\mathrm{C}-\mathrm{N}$ bond construction. ${ }^{3,4}$ In 1996, Yamamoto reported catalytic amide condensation using arylboronic acids, which release only water as the side product. ${ }^{5}$ This innovative discovery triggered off the research to establish highly active organoboron catalysts. ${ }^{6}$ Yet, severe limitations have confronted arylboronic acids in catalytic peptide synthesis: the reactions still suffer from insufficient catalyst performance and restrictions in the protecting and functional groups. The development of new catalysts for peptide condensation is thus still in its nascent stage, because, to date, only a few catalysts are capable of coupling carbamate-protected, heteroatom-functionalized $\alpha$-amino acids. ${ }^{6,7}$

To tackle these issues, we focused on the structure of the intermediates in organoboron-catalyzed amidation. Since Yamamoto's original mechanistic proposal, ${ }^{5}$ Brønsted acid-activation of the carbonyl group in a "monomeric" mixed anhydride I has been widely accepted. ${ }^{\mathrm{a} a \mathrm{~b}}$ In sharp contrast, Whiting and Sheppard demonstrated a more feasible intermediate based on spectroscopic observations and isolation of the mixed anhydride II. ${ }^{8 \mathrm{c}}$ The structure of II features "diboroxane", a bridged B-O-B motif, which can be formed by dehydrative dimerization of $\mathbf{I}$. This tetragonal boron species suggested bidentate Lewis acid-activation of the carboxy groups.
The pathway involving II was further supported by a more detailed spectroscopic analysis by Ishihara. ${ }^{61}$ The analogous intermediate III with a $\mathrm{B}-\mathrm{N}-\mathrm{B}$ unit within $\mathrm{B}_{3} \mathrm{NO}_{2}$ heterocycles has also been proposed by Shibasaki as a crucial structure for carboxy activation (Scheme 1A). ${ }^{6 k, 6 n, 8 d}$ However, $\alpha$-amino acids would give the lowreactive, five-membered complex $\mathbf{I V}$ through the coordination of both the acid and a proximal nitrogen toward arylboronic acids. ${ }^{\text {tb }}$ The formation of the dimerized "active" species might thereby be hampered, preventing further development of simple arylboronic acids as catalysts for peptide synthesis (Scheme 1B). To circumvent this dilemma, we envisaged the efficient bidentate carboxy activation of $\alpha$-amino acids with a $\mathrm{B}-\mathrm{C}-\mathrm{B}$ structure, leading to the design of gem-diboronic acid (denoted here as "gem-DBA") (Scheme 1C). ${ }^{9}$ Because gem-DBAs possess "pseudo-active" B-C$B$ moiety in advance, the more efficient acid activation could be expected in the presence of $N$-protecting groups of the $\alpha$-amino acids. The structural and electronic tuning of the catalyst, in respect to the central carbon, as well as the $\mathrm{B}-\mathrm{OH}$, would disclose unknown reactivity of gem-DBAs towards amidation. ${ }^{10}$

(A) Proposed Structure of the Intermediates of Boron-Catalyzed Amidation

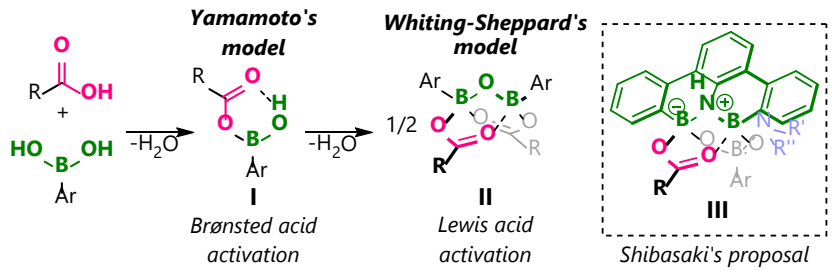

(B) Proposed Deactivation of Arylboronic Acid Catalysts with $\alpha$-Amino Acids

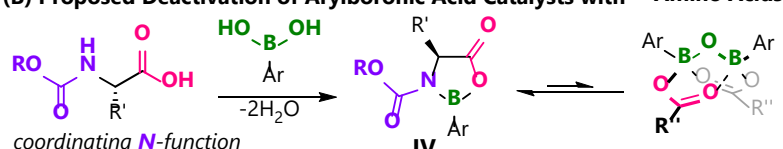

(C) This Work: Replacement of O, $\mathrm{N}$ to $\mathrm{C}$

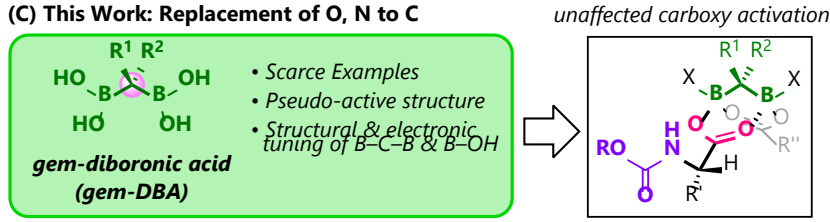

Scheme 1. Structure of the Intermediates and Catalyst Design

On the basis of the catalyst design described above, we initiated our studies by evaluating the reactivity of methylenediboronic acid (A), the simplest $\mathrm{gem}$-DBA, ${ }^{10 \mathrm{c}}$ as a catalyst. Extensive reagent screening revealed that a $5 \mathrm{~mol} \%$ of catalyst A coupled $N$-Boc-Gly (1a) with benzylamine (2) to afford amide 3a in 99\% yield in the presence of molecular sieves $5 \AA$ ( $5 \AA$ MS) in toluene at $80{ }^{\circ} \mathrm{C}$ (Table 1 , entry 1 ). Nonetheless, $N$-Boc-L-Phe (1b) was completely inert 
under the same conditions (entry 2), which prompted us to investigate the substituent effects on the central carbon atom of gem-DBA. Examination of several gem-DBAs illustrated the strong influence of steric effects around the central carbon atom: no reaction occurred with bulky catalyst B (entry 3), while relatively small monoalkyl-substituted catalyst $\mathbf{C}$ furnished $\mathbf{3 b}$ in $82 \%$ yield (entry 4 ). However, a considerable drop in the yield was observed at $65^{\circ} \mathrm{C}$ (entry 5). We assumed this lack of efficiency arose from the overbinding of amino acids to form C': bidentate activation of only two carboxy groups left two residues that would merely encumber the nucleophilic attack. Hence, we expected that the use of the orthohydroxyphenyl-substituted catalyst $\mathbf{D}$ would reduce the bulkiness around the activated carbonyls by in situ cyclocondensation to produce D'. The putative less hindered complex D' might thus exhibit higher reactivity towards the addition of amines (below Table 1). ${ }^{11}$ The catalytic performance of $\mathbf{D}$ was much greater than that of $\mathbf{C}$, affording $\mathbf{3 b}$ in $96 \%$ yield without racemization (entry 6 ). Investigation of other parameters uncovered that low-polarity solvents gave better results (entries 7-10) and lowering temperature diminished the yield (entry 11). No amidation occurred in the absence of either the catalyst or molecular sieves, indicating that the carboxy activation and the removal of water were both indispensable (entries 12 and 13)..$^{12}$

Table 1. Optimization of the Reaction Conditions.

\begin{tabular}{|c|c|c|c|c|c|}
\hline \multicolumn{2}{|c|}{$\begin{array}{c}\text { BocHN } \underbrace{\mathrm{CO}_{2} \mathrm{H}}_{\dot{\overline{\mathbf{R}}}} \\
\mathbf{1 a}(\mathrm{R}=\mathrm{H}) \\
\mathbf{1 b}(\mathrm{R}=\mathrm{Bn})\end{array}$} & \multirow{2}{*}{$\begin{array}{l}\mathbf{H}_{2} \mathbf{N} \frown \mathrm{Ph} \\
\mathbf{2} \text { (1 equiv) } \\
\text { catalyst }\end{array}$} & $\begin{array}{c}\text { catalyst }(5 \mathrm{~mol} \%) \\
\underset{5 \AA \mathrm{MS}, \text { solvent }}{\text { temp., } 12 \mathrm{~h}}\end{array}$ & \multicolumn{2}{|c|}{$\underbrace{N_{\mathbf{H}}}_{\substack{\dot{\mathbf{R}} \\
\mathbf{3 a} \text { or } \mathbf{3 b}}} \widehat{P}_{\mathrm{Ph}}^{\mathrm{BocHN}}$} \\
\hline entry & substrate & & solvent & temp. $\left({ }^{\circ} \mathrm{C}\right)$ & $3 \mathbf{b}(\%)^{a}$ \\
\hline 1 & $1 a$ & $\mathbf{A}$ & toluene & 80 & 99 \\
\hline 2 & $1 b$ & A & toluene & 80 & 0 \\
\hline 3 & $1 b$ & B & toluene & 80 & 0 \\
\hline 4 & $1 b$ & C & toluene & 80 & 82 \\
\hline 5 & $1 b$ & C & toluene & 65 & 31 \\
\hline 6 & $1 b$ & D & toluene & 65 & $96^{b}$ \\
\hline 7 & $1 b$ & D & $\mathrm{PhF}$ & 65 & 78 \\
\hline 8 & $1 b$ & D & $\left(\mathrm{CH}_{2} \mathrm{Cl}\right)_{2}$ & 65 & 68 \\
\hline 9 & $1 b$ & D & CPME & 65 & 85 \\
\hline 10 & $1 b$ & D & DMF & 65 & 0 \\
\hline 11 & $1 b$ & D & toluene & 50 & 77 \\
\hline 12 & $1 b$ & none & toluene & 65 & 0 \\
\hline $13^{c}$ & $1 b$ & D & toluene & 65 & 0 \\
\hline
\end{tabular}

Reaction conditions: 1 ( $0.20 \mathrm{mmol}, 1.0$ equiv), 2 ( $0.20 \mathrm{mmol}, 1.0$ equiv), catalyst $(10 \mu \mathrm{mol}, 5 \mathrm{~mol} \%), 5 \AA \mathrm{MS}(200 \mathrm{mg})$, solvent $(2.0 \mathrm{~mL}), 12 \mathrm{~h}$. ${ }^{a}$ Yields were determined by ${ }^{1} \mathrm{H}$ NMR analysis using 1,3,5-trimethoxybenzene as an internal standard. ${ }^{b}$ The er was estimated by chiral HPLC analysis as >99:1. ${ }^{c}$ The reaction was performed without $5 \AA$ MS.

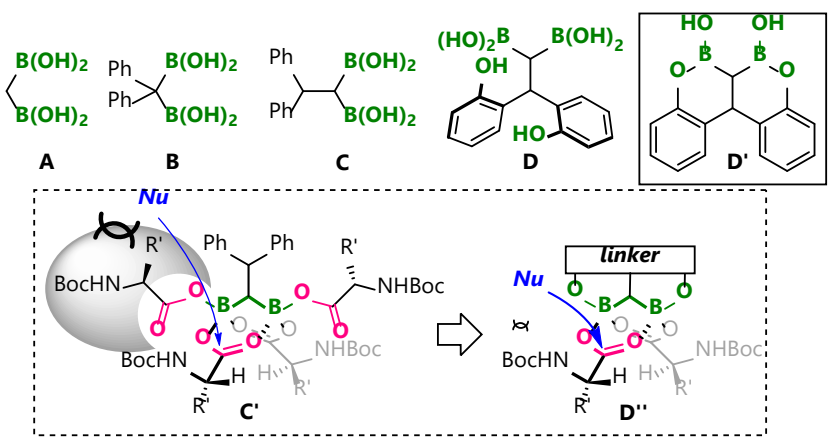

With the optimal conditions in hand, the applicability of the dehydrative amidation of $\mathbf{1 b}$ with catalyst $\mathbf{D}$ in peptide synthesis was evaluated. To our delight, the amino ester hydrochloride $4 \mathbf{a}$ was a promising nucleophile, giving dipeptide 5 ba in $88 \%$ yield at $80{ }^{\circ} \mathrm{C}$. 6l,7c The other $N$-protecting groups, including carbamates (1c, 1d), amides (1e, $\mathbf{1 f}^{\mathbf{6 l}}$ ) and a sulfonamide (1g), also afforded the corresponding dipeptides in good yields, although epimerization occurred in all cases (vide infra). The $N$-phthaloyl group (1h) was not a suitable protecting group for this system (Figure 1), in contrast to the results with arylboronic acids. ${ }^{\text {b }}$ Remarkably, in case of 1f, unprecedented catalytic dehydrative peptide synthesis at room temperature was achieved. The turnover frequency was still very low, the result suggested the feasibility of peptide condensation under mild conditions by further modification of the gem-DBA catalysts.

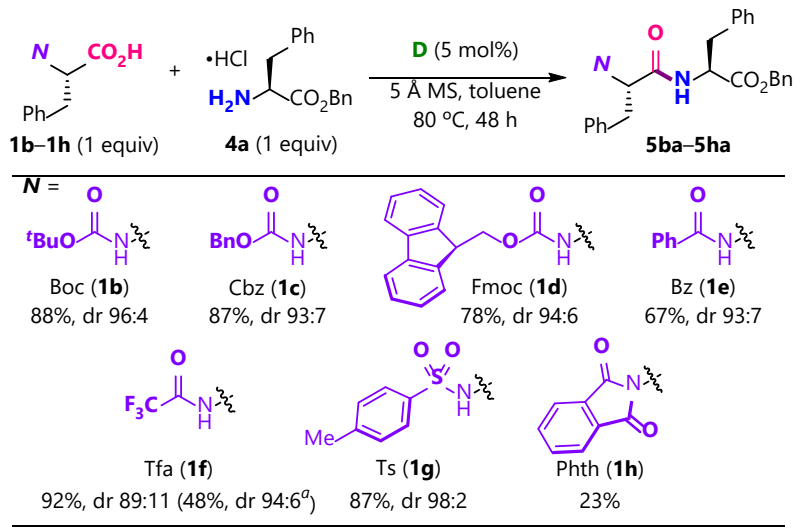

Figure 1. Variation of $\mathrm{N}$-Protecting Groups of Electrophile. Isolated yields are shown. Drs were estimated by Chiral HPLC analysis. ${ }^{a}$ The reaction was carried out using $20 \mathrm{~mol} \%$ catalyst $\mathbf{D}$ in $\mathrm{CH}_{2} \mathrm{Cl}_{2}$ at rt for $120 \mathrm{~h}$.

The potent activity of catalyst $\mathbf{D}$ toward dehydrative peptide synthesis motivated us to explore the scope of $\alpha$-amino acids endowed with various functionalized side chains (Figure 2). The coupling of $\mathrm{N}$-Boc-protected amino acids and $\mathbf{4 a}$ unveiled that $\mathbf{1 b}$ underwent the amidation at $65{ }^{\circ} \mathrm{C}$ to give $\mathbf{5 b a}$ in better yield than the reaction at $80^{\circ} \mathrm{C}$. Notably, a terminal alkyne (1i), a sulfide (1j), an ester (1k), and an amide (1) were compatible, providing the corresponding dipeptides 5ia-5la in good yields. In addition, the presence of imidazole nitrogen did not affect the formation of $5 \mathrm{ma}$. Furthermore, though a prolonged reaction time was necessary, $N$-Boc-L-proline provided the corresponding dipeptide 5 na in $73 \%$ yield. The versatility of gem-DBA towards the amino ester counterparts was next probed using 1b. Importantly, a range of alkyl-substituted nucleophiles could be applied, giving the leucine derivative $\mathbf{5 b b}$, as well as the bulky valine- and tert-leucine-derived dipeptides $\mathbf{5 b c}$ and 5bd in good yields. The cyclopropane ring in 5be survived, and protected tyrosine (5bf) and lysine (5bg) were also tolerated. Moreover, the nucleophiles bearing unprotected thiol (5bh) and indole (5bi) groups also underwent the amidation, which could offer further direct transformations of the side chains. Markedly, the temperature could be lowered to $65^{\circ} \mathrm{C}$ for $5 \mathbf{b b}$ and $5 \mathbf{b e}$. For all reactions of dipeptide synthesis, the commercial amine $\cdot \mathrm{HCl}$ salts could be directly engaged in the catalytic amidation, enabling a simple protocol free from pre-treatments and external bases. Meanwhile, significant counteranion effects were realized that $\mathbf{5 b}$ bas obtained in high yield with $\mathrm{HCl}$ salt $\mathbf{4} \mathbf{b}$, whereas the efficiency was drastically deteriorated with the different counteranion analogues of $\mathbf{4 b}$ (e.g. HBr or HOTs salts). ${ }^{13,14}$ 


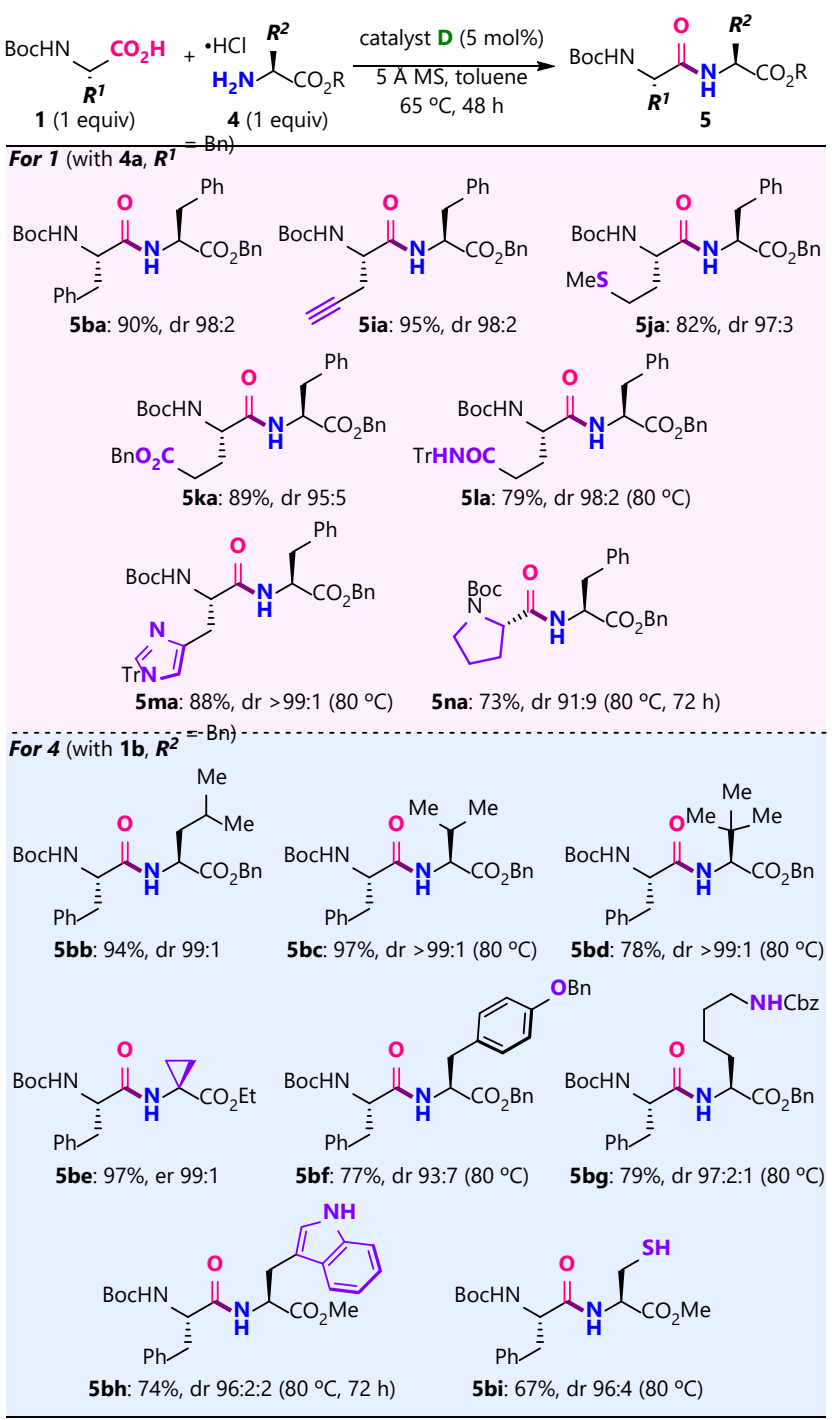

Figure 2. Scope of $N$-Boc Amino Acids 1 in Dipeptide Synthesis with 4a. Isolated yields are shown. Drs were estimated by chiral HPLC analysis.

The remarkable performance of gem-DBAs towards activation of $\alpha$-amino acids provided the opportunity for catalytic oligopeptide synthesis (Scheme 2). ${ }^{7 \mathrm{c}}$ Several studies revealed the crucial effect of the protecting groups for both the $N$ - and $C$-termini. ${ }^{4 c, 4 e, 6 m, 7 b}$ Since the electron-rich $N$-Boc protection hampered the amidation of dipeptide carboxylic acids, we prepared the electron-withdrawing $N$-trifluoroacetyl-protected $\mathbf{5 f j}$ by coupling $\mathbf{1 f}$ and $\mathbf{4 j}$. ${ }^{6 l}$ For the $C$-terminus of the dipeptide nucleophile, a tert-butyl ester protection was suitable to avoid intramolecular cyclization. ${ }^{15}$ The dipeptide 5ok was thus prepared, and after deprotection, catalytic interconnection of dipeptide segments successfully provided tetrapeptide $\mathbf{6}$ in moderate yield with a high catalyst loading. In particular, this Fmoc-based method would be expedient for the application of the gem-DBA catalysis in solid-phase peptide synthesis. ${ }^{16,17}$

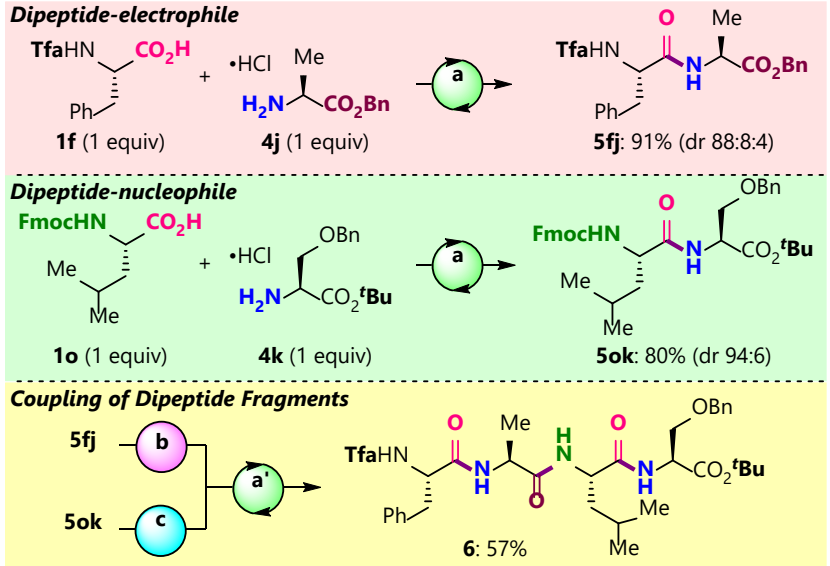

Scheme 2. Catalytic Coupling of the Dipeptide-Derived Electrophile and Nucleophile

Reaction conditions: a) catalyst D (5 mol\%), $5 \AA$ MS, toluene, $80^{\circ} \mathrm{C}, 48 \mathrm{~h}$; a') catalyst D (15 mol\%), $5 \AA \mathrm{MS}$, toluene, $80^{\circ} \mathrm{C}$, $48 \mathrm{~h}$; b) $10 \% \mathrm{Pd} / \mathrm{C}(10$ mol\% Pd), THF, rt, $\mathrm{H}_{2}$ (1 atm); c) piperidine, DMF, rt.

Generally, reagent-driven and boron-catalyzed peptide synthesis frequently induce considerable epimerization of the electrophiles. ${ }^{18,19}$ Indeed, the epimerization-prone cysteine and aspartic acid-derived electrophiles underwent approximately $20 \%$ of enantiopurity loss by strong carboxy activation with the electron-deficient boron catalysts ${ }^{61,7 \mathrm{~d}}$ and the $\mathrm{B}_{3} \mathrm{NO}_{2}$ heterocycle. ${ }^{7 \mathrm{c}}$ In marked contrast, the gem-DBA catalysis significantly suppressed the stereochemical erosion of aspartic acid derivatives $\mathbf{1 p}$ and $\mathbf{1 q}$ as well as the cysteine electrophile 1r (Scheme 3A). Meanwhile, enantiopurity of the nucleophiles was eroded, which was supported by the independent exposure of electrophile $\mathbf{1 b}$ or neutralized nucleophile 4a' or amide 5ba to the optimal conditions, leading to a slight racemization of only $\mathbf{4 a}$ ' (Scheme $3 \mathrm{~B}$ ). ${ }^{20}$ The reagent sensitivity trend toward epimerization was inverted under the gem-DBA catalysis, offering a complementary alternative to the known boron catalysts that promote epimerization of the electrophiles.

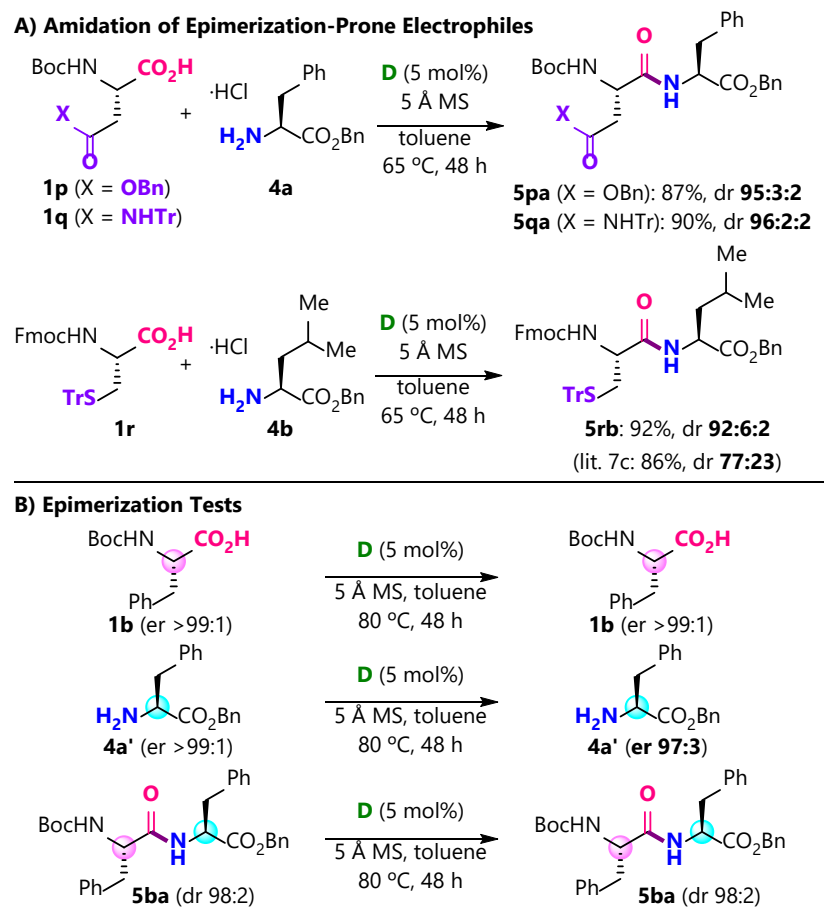

Scheme 3. Sensitivity of the Electrophiles and Nucleophiles toward Epimerization Under the gem-DBA Catalysis 
The above unusual behavior of gem-DBA led us to attempt to observe the intermediates to gain mechanistic insights into the reaction. First, the phenolic protons were quickly disappeared upon the treatment of $\mathbf{D}$ with $5 \AA$ MS in toluene- $d_{8}$ to give cis-D', and the structure was unambiguously determined by $\mathrm{X}$-ray crystallography. ${ }^{21,22}$ cis-D' possesses a bent HO-BCB-OH unit, which was theoretically more stable than trans-D' by $c a$. $9 \mathrm{kcal} / \mathrm{mol}$, consistent with the obtained structure. ${ }^{23}$ Remarkably, no dehydration of cis-D' and $\mathbf{1 b}$ occurred even in the presence of $5 \AA$ MS and excess $1 \mathbf{b}$ (1 5 equiv). Both the two boron atoms of cis-D' remained trigonal in ${ }^{11} \mathrm{~B}$ NMR analysis. The inertness of cis-D' toward $\mathbf{1 b}$ would be attributed to the lower Lewis acidity of gem-diborylalkane moiety relative to the arylboronic acids that easily form mixed anhydrides with carboxylic acids. ${ }^{61,7 \mathrm{c}}$ Instead, equimolar amount of cis-D', $\mathbf{1 b}$, and proton sponge in toluene- $d_{8}$ produced new species. The observed negative chemical shift of $\mathrm{B}-\mathrm{CH}-\mathrm{B}$ proton was consistent with the proximity of boronate anions. ${ }^{24}$ The ${ }^{11} \mathrm{~B}$ NMR analysis revealed that both the two boron atoms became tetragonal. However, switching the solvent to $\mathrm{CDCl}_{3}$ gave a different species with unsymmetrical aromatic protons of cis-D', and ${ }^{11} \mathrm{~B}$ NMR showed the existence of both trigonal and tetragonal boron atoms. ${ }^{21}$ Moreover, the negative ESI-MS spectroscopy of the mixture represented a $\mathrm{m} / \mathrm{z}$ peak at 512.2032 , implying the existence of a dehydrated complex $\mathbf{E}$ consisting of cis-D' and $\mathbf{1 b}$ in 1:1 ratio ([M] $]^{-}$: calcd $m / z=512.2057$ ) (Scheme 4). ${ }^{6 o}$ Although the structure of $\mathbf{E}$ is still unclear, the spectroscopic aspects would indicate a unique bidentate "carboxylate-activation" nature of gem-DBAs, orthogonal to arylboronic acids and $\mathrm{B}_{3} \mathrm{NO}_{2}$ heterocycles activating carboxylic acids. ${ }^{6 g}, 60,7 \mathrm{~d}$ The anion-binding property would give rise to suppress epimerization of the electrophiles, while the epimerization of nucleophiles might be induced by the coordination of amines to the boron atoms. Besides analytically, catalytic amidation of $\mathbf{1} \mathbf{b} / \mathbf{4 b}$ ' salt proceeded, whereas a proton source was necessary for the reaction of the quaternary ammonium salt (Schemes S1 and S4). Thus, gem-DBAs involve the acid/base "salt form" into the catalytic cycle, where the proton source might play a crucial role for the reaction progress. The distinctive reactivity of gem-DBAs would open prospects for catalyst modifications based on unconventional approaches in respect to their propensity as anion acceptors.

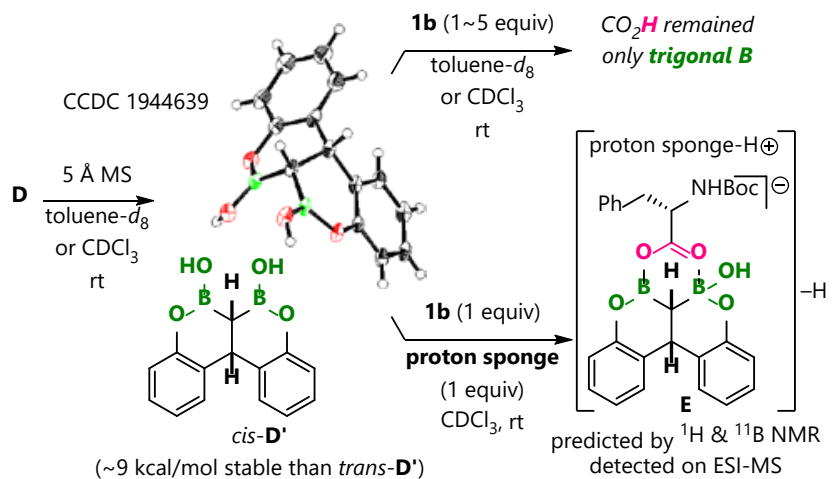

Scheme 4. Preliminary Attempts to Gain Mechanistic Insights

In summary, we have developed gem-DBAs as peptide condensation catalysts, which successfully connected a variety of functionalized $\alpha$-amino acids with suppressed epimerization of electrophiles. The first example of catalytic dehydrative peptide synthesis at room temperature is also described. The catalytic coupling of peptide segments with appropriate protecting groups manifested the feasibility of solid-phase peptide synthesis under the gem-DBA catalysis. In addition, preliminary spectroscopic studies indicated an "anion-binding" nature of gem-DBA, which clearly differs from arylboronic acid catalysis. Further research to improve the catalytic activity of gem-DBAs, including catalyst modification and mechanistic studies, is actively ongoing in our laboratory, and the results will be reported in due course.

\section{ASSOCIATED CONTENT}

\section{Supporting Information}

The Supporting Information is available free of charge on the ACS Publications website at http://pubs.acs.org.

$\mathrm{X}$-ray data file (CIF)

Experimental procedures and analytical data for all new compounds.

\section{AUTHOR INFORMATION}

\section{Corresponding Author}

*E-mail: takemoto@pharm.kyoto-u.ac.jp

ORCID

Kenichi Michigami: 0000-0001-8025-0461

Yoshiji Takemoto: 0000-0003-1375-3821

\section{Notes}

The authors declare no competing financial interests.

\section{ACKNOWLEDGMENTS}

This work was financially supported by JSPS KAKENHI, grant numbers JP16H06384 and JP19K16315. We thank Dr. Hiroyasu Sato (Rigaku Corporation) for analyzing the X-ray structures.

\section{REFERENCES}

(1) For selected reviews on reagent-driven amidation: (a) Montalbetti, C. A. G. N.; Falque, V. Amide Bond Formation and Peptide Coupling. Tetrahedron 2005, 61, 10827-10852. (b) Valeur, E.; Bradley, M. Amide Bond Formation: Beyond the Myth of Coupling Reagents. Chem. Soc. Rev. 2009, 38, 606631. (c) El-Faham, A.; Albericio, F. Peptide Coupling Reagents, More than a Letter Soup. Chem. Rev. 2011, 111, 6557-6602. (d) Dunetz, J. R.; Magano, J.; Weisenburger, G. A. Large-Scale Applications of Amide Coupling Reagents for the Synthesis of Pharmaceuticals. Org. Process Res. Dev. 2016, 20, 140-177.

(2) (a) Cooper, T. W. J.; Campbell, I. B.; Macdonald, S. J. F. Factors Determining the Selection of Organic Reactions by Medicinal Chemists and the Use of These Reactions in Arrays. Angew. Chem., Int. Ed. 2010, 49, 8082-8091. (b) Roughley, S. D.; Jordan, A. M. The Medicinal Chemist's Toolbox: An Analysis of Reactions Used in the Pursuit of Drug Candidates. J. Med. Chem. 2011, 54, 3451-3479. (c) Brown, D. G.; Boström, J. Analysis of Past and Present Synthetic Methodologies on Medicinal Chemistry: Where Have All the New Reactions Gone? J. Med. Chem. 2016, 59, 4443-4458.

(3) For selected reviews on non-classical amide bond formation: (a) Pattabiraman, V. R.; Bode, J. W. Rethinking Amide Bond Synthesis. Nature 2011, 480, 471-479. (b) Allen, C. L.; Williams, J. M. J. Metal-Catalyzed Approaches to Amide Bond Formation. Chem. Soc. Rev. 2011, 40, 3405-3415. (c) Lundberg, H.; Tinnis, F.; Selander, N.; Adolfsson, H. Catalytic Amide Formation from Non-Activated Carboxylic Acids and Amines. Chem. Soc Rev. 2014, 43, 2714-2742. (d) de Figueiredo, R. M.; Suppo, J.-S.; Campagne, J.-M. Nonclassical Routes for Amide Bond Formation. Chem. Rev. 2016, 116, 12029-12122.

(4) For recent examples of non-classical amidation of carboxylic acids and their surrogates: (a) Hu, L.; Xu, S.; Zhao, Z.; Yang. Y.; Peng, Z.; Yang, M.; Wang. C.; Zhao, J. Ynamides as Racemization-Free Coupling Reagents for Amide and Peptide Synthesis. J. Am. Chem. Soc. 2016, 138, 13135-13138. (b) Tsuji, 
H.; Yamamoto, H. Hydroxy-Directed Amidation of Carboxylic Acid Esters Using a Tantalum Alkoxide Catalyst. J. Am. Chem. Soc. 2016, 138, 14218-14221. (c) Tsuji, H.; Yamamoto, H. Synthesis of Dipeptides by Boronic Acid Catalysis. Synlett 2017, 29, 318-321. (d) Cheung, C. W.; Ploeger, M. L.; Hu, X. Direct Amidation of Esters with Nitroarenes. Nat. Commun. 2017, 8, 14878. (e) Muramatsu, W.; Tsuji, H.; Yamamoto, H. Catalytic Peptide Synthesis: Amidation of $\mathrm{N}$-Hydroxyimino Esters. ACS Catal. 2018, 8, 2181-2187. (f) Li, G.; Szostak, M. Highly Selective Transition-Metal-Free Transamidation of Amides and Amidation of Esters at Room Temperature. Nat. Commun. 2018, 9, 4165. (g) Muramatsu, W.; Hattori, T.; Yamamoto, H. SubstrateDirected Lewis-Acid Catalysis for Peptide Synthesis. J. Am. Chem. Soc. 2019, 141, 12288-12295. See also ref. 3d and references cited therein.

(5) (a) Ishihara, K.; Ohara, S.; Yamamoto, H. 3,4,5-Trifluorobenzeneboronic Acid as an Extremely Active Amidation Catalyst. J. Org. Chem. 1996, 61, 4196-4197. (b) Ishihara, K.; Ohara, S.; Yamamoto, H. (3,4,5-Trifluorophenyl)boronic Acid-Catalyzed Amide Formation from Carboxylic Acids and Amines: $\mathrm{N}$ Benzyl-4-phenylbutylamide. Org. Synth. 2002, 79, 176-185.

(6) For selected examples of organoboron-catalyzed amide condensation: (a) Maki, T.; Ishihara, K.; Yamamoto, H. Arylboronic Acid-Catalyzed Direct Condensation of Carboxylic Acids with Ureas. Synlett 2004, 2004, 1355-1358. (b) Maki, T.; Ishihara, K.; Yamamoto, H. 4,5,6,7-Tetrachlorobenzo[d][1,3,2]di-oxaborol-2-ol as an Effective Catalyst for the Amide Condensation of Sterically Demanding Carboxylic Acids. Org. Lett. 2006, 8, 1431-1434. (c) Arnold, K.; Davies, B.; Giles, R. L.; Grosjean, C.; Smith, G. E.; Whiting, A. To Catalyze or Not to Catalyze? Insight into Direct Amide Bond Formation from Amines and Carboxylic Acids under Thermal and Catalyzed Conditions. Adv. Synth. Catal. 2006, 348, 813-820. (d) Arnold, K.; Davies, B.; Hérault, D.; Whiting, A. Asymmetric Direct Amide Synthesis by Kinetic Amine Resolution: A Chiral Bifunctional Aminoboronic Acid Catalyzed Reaction between a Racemic Amine and an Achiral Carboxylic Acid. Angew. Chem., Int. Ed. 2008, 47, 2673-2676. (e) Al-Zoubi, R. M.; Marion, O. Hall, D. G. Direct and Waste-Free Amidations and Cycloadditions by Organocatalytic Activation of Carboxylic Acids at Room Temperature. Angew. Chem., Int. Ed. 2008, 47, 28762879. (f) Gernigon, N.; Al-Zoubi, R. M.; Hall, D. G. Direct Amidation of Carboxylic Acids Catalyzed by ortho-Iodo Arylboronic Acids: Catalyst Optimization, Scope, and Preliminary Mechanist Study Supporting a Peculiar Halogen Acceleration Effect. J. Org. Chem. 2012, 77, 8386-8400. (g) Yamashita, R.; Sakakura, A.; Ishihara, K. Primary Alkylboronic Acids as Highly Active Catalysts for the Dehydrative Amide Condensation of $\alpha$-Hydroxycarboxylic Acids. Org. Lett. 2013, 15, 36543657. (h) Tam, E. K. W.; Rita; Liu, L. Y.; Chen, A. 2-Furanylboronic Acid as an Effective Catalyst for the Direct Amidation of Carboxylic Acids at Room Temperature. Eur. J. Org. Chem. 2015, 2015, 1100-1107. (i) El Dine, T. M.; Erb, W.; Berhault, Y.; Rouden, J.; Blanchet, J. Catalytic Chemical Amide Synthesis at Room Temperature: One More Step Toward Peptide Synthesis. J. Org. Chem. 2015, 80, 4532-4544. (j) Ishihara, K. Lu, Y. Boronic Acid-DMAPO Cooperative Catalysis for Dehydrative Condensation between Carboxylic Acid and Amines. Chem. Sci. 2016, 7, 1276-1280. (k) Noda, H.; Furutachi, M.; Asada, Y.; Shibasaki, M.; Kumagai, N, Unique Physicochemical and Catalytic Properties Dictated by the $\mathrm{B}_{3} \mathrm{NO}_{2}$ Ring System. Nat. Chem. 2017, 9, 57-63. (l) Wang, K.; Lu, Y.; Ishihara, K. The ortho-Substituent on 2,4-Bis(trifluoromethyl)phenylboronic Acid Catalyzed Dehydrative Condensation between Carboxylic Acids and Amines. Chem. Commun. 2018, 54, 5410-5413. (m) Sawant, D. N.; Bagal, D. B.; Ogawa, S.; Selvam, K.; Saito, S. Diboron-Catalyzed Dehydrative Amidation of Aromatic Carboxylic Acids with Amines. Org. Lett. 2018, 20, 4397-4400. (n) Opie, C. R.; Noda, H.; Shibasaki, M.; Kumagai, N. All Non-
Carbon $\mathrm{B}_{3} \mathrm{NO}_{2}$ Exotic Heterocycles: Synthesis, Dynamics, and Catalysis. Chem. Eur. J. 2019, 25, 4648-4653. (o) Shimada, N.; Hirata, M.; Koshizuka, M.; Ohse, N.; Kaito, R.; Makino, K. Diboronic Acid Anhydrides as Effective Catalysts for the Hydroxy-Directed Dehydrative Amidation of Carboxylic Acids. Org. Lett. 2019, 21, 4303-4308.

(7) (a) Liu, S.; Yang, Y.; Liu, X.; Ferdousi, F. K.; Batsanov, A. S.; Whiting, A. Direct Amidation of Amino Acid Derivatives Catalyzed by Arylboronic Acids: Application in Dipeptide Synthesis. Eur. J. Org. Chem. 2013, 2013, 5692-5700. (b) Fatemi, S.; Gernigon, N.; Hall, D. G. A Multigram-Scale Lower E-Factor Procedure for MIBA-Catalyzed Direct Amidation and its Application to the Coupling of Alpha and Beta Aminoacids. Green Chem. 2015, 17, 4016-4028. (c) Liu, Z.; Noda, H.; Shibasaki, M.; Kumagai, N. Catalytic Oligopeptide Synthesis. Org. Lett. 2018, 20, 612-615. (d) Sabatini, M. T.; Karaluka, V.; Lanigan, R. M.; Boulton, L. T.; Badland, M.; Sheppard, T. D. Protecting-Group-Free Amidation of Amino Acids Using Lewis Acid Catalysts. Chem. Eur. J. 2018, 24, 7033-7043.

(8) (a) Marcelli, T. Mechanistic Insights into Direct Amide Bond Formation Catalyzed by Boronic Acids: Halogen as Lewis Bases. Angew. Chem., Int. Ed. 2010, 49, 6840-6843. (b) Wang, C.; Yu, H.-Z.; Fu, Y.; Guo, Q.-X. Mechanism of Arylboronic Acid-Catalyzed Amidation Reaction between Carboxylic Acids and Amines. Org. Biomol. Chem. 2013, 11, 2140-2146. (c) Arkhipenko, S.; Sabatini, M. T.; Batsanov, A. S.; Karaluka, V.; Sheppard, T. D.; Rzepa, H. S.; Whiting, A. Mechanistic Insights into Boron-Catalyzed Direct Amidation Reactions. Chem. Sci. 2018, 9, 1058-1072. (d) Noda, H.; Asada, Y.; Shibasaki, M.; Kumagai, N. Neighboring Protonation Unveils Lewis Acidity in the $\mathrm{B}_{3} \mathrm{NO}_{2}$ Heterocycle. J. Am. Chem. Soc. 2019, 141, 15461554.

(9) For recent reviews on the synthesis and reactivity of gemdiboron compounds: (a) Wu, C.; Wang, J. Geminal Bis(boron) Compounds: Their Preparation and Synthetic Applications. Tetrahedron Lett. 2018, 59, 2128-2140. (b) Miralles, N.; Maza, R. J.; Fernández, E. Synthesis and Reactivity of 1,1-Diborylalkanes toward C-C Bond Formation and Related Mechanisms. Adv. Synth. Catal. 2018. 360, 1306-1327. (c) Nallagonda, R.; Padala, K.; Masarwa, A. gem-Diborylalkanes: Recent Advances in Their Preparation, Transformation and Application. Org. Biomol. Chem. 2018, 16, 1050-1064.

(10) (a) Matteson, D. S.; Shdo, J. G. gem-Dimetallic Compounds. Ethane-1,1-Diboronic Acid and Ethylidenedimercuric Chloride. J. Org. Chem. 1964, 29, 2742-2746. (b) Matteson, D. S.; Moody, R. J. Deprotonation of 1,1-Diboronic Esters and Reactions of the Carbanions with Alkyl Halides and Carbonyl Compounds. Organometallics 1982, 1, 20-28. (c) Ali, H. A.; Goldberg, I.; Srebnik, M. Addition Reactions of Bis(pinacolato)diborane(4) to Carbonyl Enones and Synthesis of (pinacolato $)_{2} \mathrm{BCH}_{2} \mathrm{~B}$ and (pinacolato) ${ }_{2} \mathrm{BCH}_{2} \mathrm{CH}_{2} \mathrm{~B}$ by Insertion and Coupling. Organometallics 2001, 20, 3962-3965.

(11) (a) Dohi, T.; Kamitanaka, T.; Watanabe, S.; Hu, Y.; Washimi, N.; Kita, Y. Efficient Synthesis of Oxygenated Terphenyls and Other Oligomers: Sequential Arylation Reactions Through Phenol Oxidation-Rearomatization. Chem. Eur. J. 2012, 18, 13614-13618. (b) Sumida, Y.; Harada, R.; Kato-Sumida, T.; Johmoto, K.; Uekusa, H.; Hosoya, T. Boron-Selective Biaryl Coupling Approach to Versatile Dibenzoxaborins and Application to Concise Synthesis of Defucogilvocarcin M. Org. Lett. 2014, 16, 6240-6243.

(12) $5 \AA$ MS provided the better result than $4 \AA$ and $3 \AA$ MS, see Table S2.

(13) For a detailed investigation of counteranion effects, see Table S3, Scheme S1 and Scheme S2.

(14) The HCl salts were fully neutralized upon treatment with $5 \AA$ MS (without catalyst), while no conversion from the other salts (e.g. $\mathrm{HBr}, \mathrm{HNO}_{3}, \mathrm{HOTs}$ ). See also ref. 6l, 7c, 19, and Scheme S3. 
(15) (a) Iyer, M. S.; Gigstad, K. M.; Namdev, N. D.; Lipton, M. Asymmetric Catalysis of the Strecker Amino Acid Synthesis by a Cyclic Dipeptide. J. Am. Chem. Soc. 1996, 118, 4910-4911. (b) Kennedy, A. L.; Fryer, A. M.; Josey, J. A. A New ResinBound Universal Isonitrile for the Ugi 4CC Reaction: Preparation and Applications to the Synthesis of 2,5-Diketopiperazines and 1,4-Benzodiazepine-2,5-diones. Org. Lett. 2002, 4, 11671170.

(16) (a) Kent, S. B. H. Chemical Synthesis of Peptides and Proteins. Ann. Rev. Biochem. 1988, 57, 957-989. (b) Palomo, J. M. Solid-Phase Peptide Synthesis: An Overview Focused on the Preparation of Biologically Relevant Peptides. RSC Adv. 2014, 4, 32658-32672. (c) Behrendt, R.; White, P.; Offer, J. Advances in Fmoc Solid-Phase Peptide Synthesis. J. Pept. Sci. 2016, 22, 4-27.

(17) (a) Maki, T.; Ishihara, K.; Yamamoto, H. N-Alkyl-4-boronopyridinium Salts as Thermally Stable and Reusable Amide Condensation Catalysts. Org. Lett. 2005, 7, 5043-5046. (b) Gu, L.; Lim, J.; Cheong, J. L.; Lee, S. S. MCF-Supported Boronic Acids as Efficient Catalysts for Direct Amide Condensation of Carboxylic Acids and Amines. Chem. Commun. 2014, 50, 7017-7019. (c) Lu, Y.; Wang, K.; Ishihara, K. Design of Boronic Acid-Base Complexes as Reusable Homogenous Catalysts in Dehydrative Condensations between Carboxylic Acids and Amines. Asian J. Org. Chem. 2017, 6, 1191-1194. (d) Du, Y.; Barber, T.; Lim, S. E.; Rzepa, H. S.; Baxendale, I. R.; Whiting, A. A Solid-Supported Arylboronic Acid Catalyst for Direct Amidation. Chem. Commun. 2019, 55, 2916-2919.

(18) Goodman, M.; McGahren, W. J. Mechanistic Studies of Peptide Oxazolone Racemization. Tetrahedron 1967, 23, 2031 2050.
(19) (a) Barber, M.; Jones, J. H.; Witty, M. J. Structural Factors Affecting the Direct Exchange Racemization of Benzyloxycarbonyl-S-Benzyl-L-Cysteine Pentachlorophenyl Ester and Related Compounds by Triethylamine in Chloroform. J. Chem. Soc., Perkin Trans. 1 1979, 1979, 2425-2428. (b) Reszka, P.; Methling, K.; Lalk, M.; Xiao, Z.; Weisz, K.; Bednarski, P. Control of Aspartate Epimerization during the Coupling of Caspase Specific Tetrapeptides with Aromatic Amines by Using $N$-[[(dimethylamino)-1H-1,2,3-triazolo[4,5- $b$ ]-pyridin-1-yl]methylene]- $N$-methylmethanaminium Hexafluorophosphate $N$-oxide (HATU) as a Coupling Reagent. Tetrahedron: Asymmetry 2008, 19, 49-59.

(20) 4a (HCl salt) also underwent a slight racemization under the same conditions with full neutralization. For a detailed investigation, see Scheme S3.

(21) For detailed NMR and ESI-MS studies, see the Supporting Information.

(22) The crystal twinning occurred with cis-D’ likely due to the axial chirality. For the details of X-ray structure, see the Supporting Information.

(23) All levels of DFT calculation performed gave 8.5 9.3 $\mathrm{kcal} / \mathrm{mol}$ lower energy values for cis-D' than for trans-D'. For the details of calculations, see the Supporting Information.

(24) (a) Köster, R.; Seidel, G.; Boese, R.; Wrackmeyer, B. Substituierte 2,5-Dihydro-1,2,5-oxasilaborole - Herstellung, Komplexierungen und Ringöffnung. Chem. Ber. 1988, 121, 597-615. b) Köster, R.; Sporzyński, A.; Schüßler, W.; Bläser, D.; Boese, R. Chelat-stabilisierte 1,3-Bis(acyloxy)-1,3-diethyldiboroxane aus Triethylboroxin und Carbonsäureanhydriden. Chem. Ber. 1994, 127, 1191-1199.

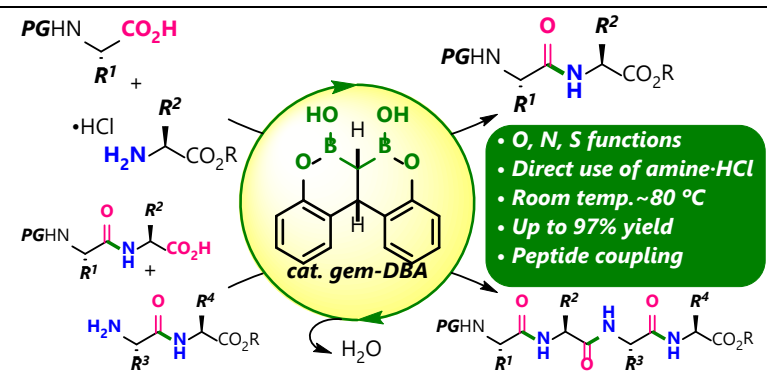

Insert Table of Contents artwork here 